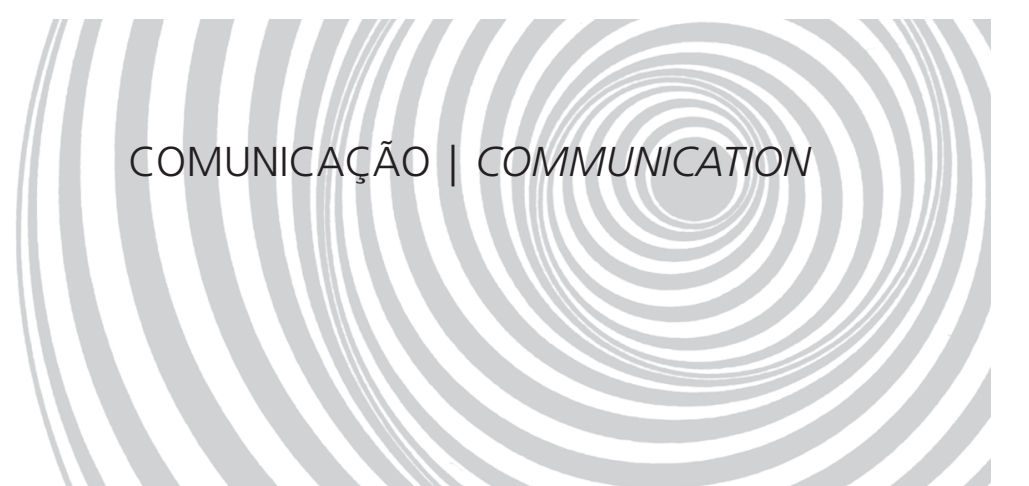

\title{
Pode a atividade física materna modular a programação fetal induzida pela nutrição?
}

\author{
Can maternal physical activity modulate the \\ nutrition-induced fetal programming?
}

Carol Góis LEANDRO ${ }^{1}$

Marco Fidalgo AMORIM ${ }^{2}$

Sandro Massao HIRABARA ${ }^{3}$

Rui CURI ${ }^{4}$

Raul MANHÃES DE CASTRO²

\section{RE S U M O}

Existe considerável evidência para a indução de diferentes fenótipos em reposta às variações no ambiente fetal e neonatal. O aporte inadequado de nutrientes no período crítico do desenvolvimento está associado ao risco alto de doenças metabólicas na vida adulta, este fenômeno biológico é chamado de programação. A atividade física durante a gestação resulta em adaptações fisiológicas da mãe e no aumento da disponibilidade de nutrientes e oxigênio no espaço feto-placentário. Este trabalho tem como objetivo discutir os mecanismos da indução de programação fetal pela nutrição e o provável efeito modulador da atividade física durante a gestação. Foram utilizadas as bases de dados do Medline Pubmed, Lilacs e Bireme, com publicações entre 1990 até 2008. Os termos de indexação utilizados foram: nutrition, fetal programming, gestation, physical activity, physical exercise, metabolism. Em conclusão, o aporte inadequado de nutrientes programa o aparecimento de doenças metabólicas na vida adulta, enquanto que a atividade física durante a gestação aumenta a disponibilidade de nutrientes e oxigênio, repercutindo positivamente no crescimento fetal e no peso ao nascer.

Termos de indexação: Atividade motora. Desenvolvimento fetal. Fenótipo. Gestação.

A B S T R A C T

There is considerable evidence for the induction of different phenotypes by variations in fetal and neonatal environment. Undernutrition during this critical development period is associated with risk of metabolic

\footnotetext{
1 Universidade Federal de Pernambuco, Centro Acadêmico de Vitória de Santo Antão, Núcleo de Nutrição. R. Prof. Moraes Rego, 1235, Cidade Universitária, 50670-901, Recife, PE, Brasil. Correspondência para/Correspondence to: C.G. LEANDRO: E-mail: <carolleandro22@yahoo.com.br>.

2 Universidade Federal de Pernambuco, Departamento de Nutrição. Recife, PE, Brasil.

${ }^{3}$ Universidade Cruzeiro do Sul, Instituto de Ciências da Atividade Física e do Esporte, Departamento de Educação Física. São Paulo, SP, Brasil.

${ }^{4}$ Universidade de São Paulo, Instituto de Ciências Biomédicas. São Paulo, SP, Brasil.
} 
560 | C.G. LEANDRO et al.

disease in adult life; this biological phenomenon is termed programming. Physical activity during gestation results in maternal physiological adaptations and increased oxygen and nutrients in the fetoplacental compartment. The main goal of this work is to discuss the mechanisms of fetal programming induced by nutrition and the probable modulating effect of physical activity during gestation. Papers published between 1990 and 2008 listed in the Medline Pubmed, Lilacs and Bireme databases were used. The search keywords were: nutrition, fetal programming, gestation, physical activity, physical exercise, and metabolism. In conclusion, undernutrition can program the onset of metabolic diseases in adult life, while physical activity during gestation increases the availability of nutrients and oxygen for the fetus, thereby positively impacting fetal growth and birth weight.

Indexing terms: Motor activity. Fetal development. Phenotype. Pregnancy.

\section{N T R O D U Ç Ã O}

Uma alimentação balanceada é essencial nas etapas de crescimento e desenvolvimento do organismo. A falta ou a deficiência de nutrientes em períodos críticos do desenvolvimento dos sistemas fisiológicos, durante a gestação e a lactação, tem repercussões a curto e longo prazo. A desnutrição no período fetal e na infância predispõe o indivíduo adulto a doenças cardiovasculares e diabetes tipo II, ou aos fatores de risco associados, como a hipertensão, a intolerância à glicose e a hiperlipidemia'. O organismo se adapta a um ambiente intra-uterino adverso, otimizando a utilização de nutrientes para assegurar sua sobrevivência. Se há aumento na disponibilidade de nutrientes após esse período crítico, o organismo pode apresentar alterações metabólicas associadas à obesidade e ao diabetes tipo II'.

O mecanismo envolvido ainda está pouco esclarecido, mas pode estar associado a uma programação, na qual um estímulo ambiental aplicado durante o período crítico de desenvolvimento, tem efeito subseqüente sobre estruturas e funções de sistemas orgânicos ${ }^{2}$. Outro mecanismo proposto é que um ambiente nutricional pode estimular uma seleção clonal adaptativa ou a proliferação e a diferenciação celulares, de forma que a quantidade e a proporção de células em um tecido sejam permanentemente afetadas. A epigenética estuda a interação entre o ambiente (fenótipo) e a expressão de genes (genótipo) ${ }^{3}$.

A identificação da regulação epigenética de expressão de genes como potencial meca- nismo da indução de diferentes fenótipos pela nutrição materna durante o período crítico do desenvolvimento suscita o questionamento sobre a atuação de outros estímulos ambientais. Nesse sentido, é importante questionar acerca do estilo de vida materno, que inclui o engajamento em programas de atividade física. Os estudos citados neste texto indicam que a atividade física materna e o aporte energético induzem adaptações fisiológicas na gestação e atuam como reguladores crônicos e agudos da disponibilidade de oxigênio e substrato para o binômio mãe-filho. Parece que o principal fator que inicia a seqüência reguladora do crescimento é a disponibilidade de substrato e oxigênio vindos da mãe.

Diante da importância do estilo de vida materno para o desenvolvimento feto-placentário, levantou-se a hipótese sobre os mecanismos de programação fetal induzida pela atividade física e as repercussões na vida adulta. Da mesma forma, será que a atividade física materna pode modular a programação fetal induzida pela desnutrição? Para realização desta revisão, utilizaram-se as bases de dados Medline Pubmed, Lilacs e Bireme. Os termos de indexação utilizados foram: nutrition, fetal programming, gestation, physical activity, physical exercise, metabolism. Os artigos foram selecionados de acordo com a relevância do estudo para os tópicos estudados. Os artigos selecionados incluem estudos clássicos sobre programação fetal a partir de 1962. Para a discussão sobre nutrição e atividade física durante a gestação, foram utilizados artigos publicados nos anos de 1990 até 2008. 


\section{O Q UE É PROGRAM A ÇÃ O FE T A L?}

O termo programação é utilizado para descrever o processo pelo qual um estímulo ou insulto, quando aplicado no período crítico do desenvolvimento, tem efeitos permanentes sobre a estrutura e as funções do organismo². A programação é um fenômeno biológico já bem conhecido. Por exemplo, em ratas, uma única dose de testosterona, aplicada no período crítico do desenvolvimento, programa o cérebro a desenvolver um padrão de comportamento masculino depois da puberdade, apesar de não alterar a função da pituitária e dos ovários ${ }^{4}$. O consumo de álcool por ratas gestantes causa redução de peso ao nascer e menor taxa de crescimento dos filhotes ${ }^{5}$. Este grupo de pesquisadores tem verificado em ratos que a exposição a fármacos durante o período crítico do desenvolvimento induz alterações na vida adulta. Por exemplo, durante o período crítico de desenvolvimento do sistema nervoso central, a administração crônica de citalopran, um anti-depressivo inibidor seletivo da recaptação de serotonina, reduziu o comportamento agressivo de ratos adultos ${ }^{6}$. O uso de outro anti-depressivo, a fluoxetina, durante a lactação, reduziu o comportamento depressivo de ratos adultos ${ }^{7}$. O tratamento neonatal com naloxane, um opióide endógeno, durante o período crítico de desenvolvimento dos testículos, aumenta a população das células de Sertoli e a produção de esperma em ratos adultos ${ }^{8}$.

Em humanos, os estudos que envolvem a programação fetal geralmente associam a nutrição como estímulo indutor de programação fetal. A primeira evidência de programação veio de um estudo geográfico, em diferentes regiões da Inglaterra no ano de 1911, que associou a alta taxa de mortalidade por doenças cardiovasculares ao baixo peso ao nascer ${ }^{9}$. Este elo foi subseqüentemente demonstrado em estudos nos quais o crescimento durante a vida fetal e na infância foi registrado. 0 primeiro estudo foi realizado por Ravelli et al. ${ }^{10}$ com homens cujas mães passaram fome durante a gestação entre os anos de 1944-1945, a cha- mada Dutch famine. Os autores observaram que a exposição à fome no período da gestação resultou em jovens obesos aos 19 anos. Em Hertfordshire (Inglaterra), dentre 5654 homens, aqueles que apresentaram menor peso ao nascer tiveram maior taxa de mortalidade por doenças cardiovasculares quando adultos ${ }^{11}$. Ainda em Hertfordshire, foi observado que os homens diagnosticados como diabéticos apresentaram menor peso ao nascer e no primeiro ano de vida ${ }^{12}$. No Brasil, tendo como principal fonte de informações três estudos transversais realizados nas décadas de 70, 80 e 90, observou-se transição nutricional referenciada no declínio rápido da prevalência de desnutrição em crianças e elevação, em ritmo mais acelerado, da prevalência de sobrepeso/obesidade em adultos ${ }^{13}$.

\section{A nutrição como indutora de programação fetal}

A relação entre a nutrição no período fetal e perinatal e a repercussão na vida adulta tem sido reconhecida há várias décadas. Em 1962, McCance ${ }^{14}$ manipulou o tamanho de ninhadas de forma que ratos de grandes ninhadas receberam menos leite materno, quando comparados aos seus pares de ninhadas menores. Após o período de lactação, ambos os grupos foram alimentados com dieta equilibrada. Os ratos provindos de grandes ninhadas apresentaram menor ganho de peso corporal e redução na taxa de crescimento. Foi assim demonstrado que o tamanho e a trajetória de crescimento de ratos estavam relacionados ao seu estado nutricional no período de lactação. Foi também demonstrado que a manipulação da dieta após a lactação não induziu qualquer efeito a longo prazo nos animais. Dessa forma, surgiu a idéia de uma janela crítica temporal para o crescimento e o desenvolvimento, que pode ser programada pela nutrição ${ }^{14}$.

Uma vez reconhecido o papel dos nutrientes no crescimento e desenvolvimento, o estado nutricional de indivíduos, especialmente a desnutrição, se tornou o alvo dos estudos. Em 1964, 
Dobbing ${ }^{15}$ formulou a hipótese do período crítico do desenvolvimento, observando efeitos irreversíveis da desnutrição neonatal sobre o desenvolvimento do cérebro de ratos. De acordo com a ontogênese de cada fase (gestação, lactação ou primeira infância) e da espécie a ser estudada, a janela crítica do desenvolvimento pode se abrir e a falta ou o excesso de nutrientes pode induzir alterações permanentes na estrutura e na função de órgãos e sistemas. Em ratos, a desnutrição no período crítico de desenvolvimento do sistema nervoso, que é o período de lactação, induz efeitos permanentes sobre o tamanho do cérebro, o número de neurônios, o comportamento, a aprendizagem e a memória ${ }^{16,17}$. Estes pesquisadores têm observado que a desnutrição no período neonatal altera o crescimento somático, a resposta ao tratamento com anti-depressivos, o comportamento agressivo, o comportamento alimentar, as propriedades mecânicas do músculo esquelético, a morfologia do músculo cardíaco e o padrão de atividade locomotora de ratos adultos ${ }^{18-22}$.

Estudos experimentais sobre a desnutrição fetal têm demonstrado que fetos de mães submetidas à dieta hipoprotéica apresentam alterações metabólicas a curto e longo prazo ${ }^{23-25}$. Um modelo animal de estudo bem estabelecido é fornecer às mães uma dieta normoprotéica (com 18-20\% de proteína, caseína) ou uma dieta hipoprotéica (7\% a $8 \%$ de proteína, caseína), e no período de lactação ou no desmame, os filhotes começam a receber dieta padronizada ${ }^{26-28}$. Em um estudo com modelo de desnutrição protéica no período gestacional, foi verificado que a apoptose de células- $\beta$ estava aumentada no pâncreas dos neonatos aos 14 dias de vida ${ }^{29}$. Em ratos machos, a restrição de proteína na dieta alterou o desenvolvimento reprodutivo aos 70 dias de idade ${ }^{30}$. Em ratos adultos (135 dias de idade) submetidos a uma dieta hipoprotéica ( $8 \%$ de caseína) durante o período pré e pós-natal, foi observada uma deficiência na estrutura dos rins e menor pressão arterial média, quando comparados aos seus pares normoprotéicos $(20 \% \text { de caseína) })^{31}$.
O fígado de ratos adultos aos três meses de idade, cujas mães sofreram desnutrição gestacional, apresenta aumento no tamanho dos lóbulos. Estudos com perfusão ex-vivo têm mostrado resistência à ação estimuladora do glucagon sobre a liberação da glicose no fígado de filhotes adultos nessas condições. Este resultado foi acompanhado por redução de $80 \%$ na expressão de receptores hepáticos para o glucagon. Neste mesmo estudo, a insulina causou aumento da liberação de glicose hepática antes da redução normalmente esperada. Parece que os receptores de membrana em hepatócitos são alvos para a programação, aumentando a expressão de receptores para a insulina em resposta à restrição dietética da mãe ${ }^{26}$.

O músculo, principal local de consumo de glicose pós-prandial, tem também sido alvo de estudos. O músculo sóleo de ratos aos 15 meses de idade, e que foram submetidos à desnutrição fetal, apresenta menor sensibilidade à insulina, quando comparado ao de controles normoprotéicos. Os adipócitos de ratos (aos três meses de idade) submetidos à desnutrição na vida fetal apresentaram uma taxa elevada de consumo basal de glicose estimulado por insulina. Em paralelo, foi observado neste mesmo estudo, aumento na atividade da fosfatidilinositol 3 quinase (PI3K), que participa diretamente dos efeitos metabólicos da insulina. Apesar do aumento da atividade do PI3K, os adipócitos de filhotes submetidos à desnutrição foram resistentes à ação anti-lipolítica da insulina ${ }^{25}$.

Além do modelo de desnutrição por dieta hipoprotéica, há também o modelo de manipulação do percentual da dieta fornecida ao controle, geralmente entre 30 e $50 \%$, de acordo com o consumo normal de ratos. Utilizando o modelo de restrição da dieta (30\% da dieta consumida pelo controle ad libitum) durante a gestação e a recuperação da dieta na lactação, foi observado atraso no crescimento pós-natal e aumento na pressão arterial de ratos adultos ${ }^{32}$. Filhotes nascidos de mães alimentadas com $40 \%$ da dieta ad libitum fornecida ao grupo controle apresentaram taxa de crescimento menor, quando comparados 
ao grupo controle ${ }^{33}$. Assim, não somente em termos qualitativos (quantidade de proteína), mas a quantidade de nutrientes fornecida durante o período crítico do desenvolvimento pode induzir alterações na taxa de crescimento do filhote.

A relevância dos dados provindos de estudos com animais para humanos permanece incerta. Contudo, em estudos epidemiológicos tem sido demonstrado que a desnutrição no período fetal ou neonatal pode programar o indivíduo para um aumento ou preservação dos estoques de gordura corporal ao longo da vida9,10. Estudos recentes nos países em desenvolvimento demonstraram que os distúrbios no crescimento associados à desnutrição são paradoxalmente relacionados ao aumento do índice peso/altura ${ }^{34}$. No Brasil, foi investigada a prevalência de obesidade e desnutrição em 535 famílias (2 411 indivíduos) de uma zona de baixa renda na cidade de São Paulo ${ }^{35}$. Neste estudo, houve 30\% de prevalência de desnutrição infantil. A prevalência de obesidade foi de $6,4 \%$ em rapazes e de $8,7 \%$ em moças. A associação entre sobrepeso e deficiência no crescimento foi de $5,8 \%$ em rapazes e $6,8 \%$ para moças, ocorrendo relação forte entre peso/altura infantil e sobrepeso no adulto ${ }^{35}$. Resultados similares com crianças da zona rural e de periferias urbanas do Brasil foram publicados $^{36,37}$.

\section{MECANISMOS PROPOSTOS}

Os mecanismos envolvidos na programação incluem a interação entre o ambiente (fenótipo) e a expressão de genes (genótipo), que tem sido chamada de epigenética ${ }^{3}$. Muitos genes requerem condições especiais do ambiente para ganharem expressão fisiológica e comportamental, outros genes, provavelmente, nunca encontrarão condições adequadas de expressão ${ }^{3}$. Existem evidências de que o estado nutricional materno pode induzir alterações da expressão de genes pela metilação do DNA (ácido desoxirribonucléico) e da modificação de histonas (metilação e acetilação) do genoma fetal ${ }^{38}$. Uma questão de inte- resse é o entendimento de como a memória destes eventos é estocada ao longo da vida, apesar de uma contínua divisão e diferenciação celulares.

O fenótipo do filhote que persiste ao longo da vida implica em alterações estáveis para a transcrição do gene ${ }^{3,39}$. Embora o número de genes estudados ainda seja limitado, os efeitos estáveis da restrição de nutrientes sobre a transcrição têm sido demonstrados em alguns estudos ${ }^{3,38}$. Nesse sentido é de ressalva o papel do imprinting genômico. Os imprinted genes são genes encontrados na placenta de mamíferos, marsupiais e sementes de plantas cuja expressão depende de sua origem parental. Em mamíferos, muitos destes genes estão envolvidos no crescimento fetal e são expressos tanto em tecidos do feto como na placenta ${ }^{38}$.

É de interesse que alguns dos genes que são alterados seguindo estímulo ambiental pré e pós-natal são fatores de transcrição que afetam vias metabólicas ${ }^{3}$. Por exemplo, filhotes de mães submetidas à dieta hipoprotéica na gestação têm, aproximadamente, o dobro de atividade da enzima fosfenolpiruvato-carboxiquinase (PEPCK), uma enzima-chave da gliconeogênese, e aumento da atividade da enzima glicoquinase, uma enzima-chave da glicólise ${ }^{25}$. Ademais, o perfil lipídico alterado em filhos de mães desnutridas na gestação parece ter relação com o aumento da expressão das enzimas acetil Co-A carboxilase e ácido graxo sintase no fígado ${ }^{25}$. Tomados juntos, estes resul-tados demonstram um aumento no metabolismo hepático dos carboidratos na direção oposta daquela que seria induzida pela insulina.

A identificação da regulação epigenética de expressão de genes como potencial mecanismo da indução de diferentes fenótipos pela nutrição materna, durante o período crítico do desenvolvimento, suscita o questionamento sobre a atuação de outros estímulos ambientais. Nesse sentido, é importante questionar acerca do estilo de vida materno, que inclui o engajamento em programas de atividade física. Estudos epidemiológicos têm observado uma associação entre o estilo de vida ativo materno e as adaptações fisiológicas da gestação que regulam o crescimento feto-placentário ${ }^{40-42}$. 


\section{Atividade física durante a gestação sobre o binômio mãe-filho}

De acordo com o American College of Obstetricians and Gynecologists ${ }^{43}$, mulheres com gestação de baixo-risco podem praticar exercício físico moderado e leve por cerca de 30 minutos por dia, todos os dias da semana. Contudo, ainda é difícil estabelecer recomendações de percentual de esforço físico durante a gestação, uma vez que a intensidade, o tipo e a duração do exercício físico são determinantes para as adaptações fisiológicas na mãe e as repercussões no filho. Ademais, é necessária a definição de termos utilizados como, por exemplo, atividade física, exercício físico e treinamento físico, para o entendimento da associação entre o estilo de vida da mãe e o desenvolvimento feto-placentário.

\section{Atividade física durante a gestação}

O termo atividade física se refere a qualquer movimento do músculo esquelético que demande gasto energético. Quanto ao nível de atividade física, o indivíduo pode ser classificado como ativo ou inativo, a depender da quantidade de calorias semanais gastas em um esforço físico ${ }^{44}$. Assim, um indivíduo é considerado ativo quando se engaja em atividades físicas (caminhadas, jogging, andar de bicicleta, natação, atividades domésticas, atividades no trabalho, atividades de lazer e recreação) durante 30 minutos, levando a um dispêndio energético acima do metabolismo basal em torno de $1500 \mathrm{kcal} / \mathrm{semana}^{44}$.

Em 1993, um estudo epidemiológico demonstrou que atividade física durante a gestação estava associada ao peso ao nascer do filho ${ }^{45}$. Rao et al. ${ }^{42}$ avaliaram 797 gestantes da cidade de Pune na Índia quanto ao nível de atividade física (trabalho na agricultura, atividades domésticas e outras atividades), a partir de um questionário com pontuação para cada atividade. O resultado final foi expresso em gasto energético semanal (Kcal/sem). Neste estudo, foi observado que o nível de atividade física era inversamente relacionado ao ganho de peso materno a partir da $28^{a}$ semana de gestação ${ }^{42}$. Nos recém-nascidos, foi observado um menor peso ao nascer e redução em alguns parâmetros somáticos. Mais recentemente, Perkins et al. ${ }^{44}$ avaliaram a relação entre o nível de atividade física aeróbia (por acelerometria), o ganho de peso durante a gestação e a altura para a taxa de crescimento fetal em 51 mulheres gestantes. Neste estudo, a correlação entre a atividade física e a taxa de crescimento fetal foi inversamente proporcional $(R=-0,42$, $p<0,05)$. Crianças nascidas de mulheres no quartil mais alto de atividade física pesaram cerca de $608 \mathrm{~g}$ menos que crianças nascidas de mães do quartil menor ${ }^{44}$.

O engajamento em atividades de lazer e recreativas (natação e caminhada, três vezes por semana) está relacionado a efeitos positivos na mãe e no peso do filho ao nascer ${ }^{44,45}$. Estudos epidemiológicos relatam que a combinação entre atividade física regular e uma dieta equilibrada pode reduzir o risco de doenças na mãe, tais como: hipertensão, diabetes mellitus gestacional, desordem no desenvolvimento placentário, resposta insulina-glicose $e^{40-42,46}$. Assim, mulheres que se exercitam regularmente deveriam continuar com o mesmo volume de atividade física, aumentando suas atividades de lazer e recreação em cerca de 20 a 30 minutos com uma freqüência de 3 a 5 dias por semana ${ }^{43}$. De acordo com o American College of Obstetricians and Gynecologists ${ }^{43}$, os tipos de atividades que são recomendadas incluem: natação e bicicleta ergométrica (estacionária) por reduzirem as chances de lesão e impacto. Ademais, estudos recentes demonstraram que mulheres que já praticavam atividade física antes da gestação podem permanecer com a mesma duração e freqüência semanal, contudo, recomenda-se evitar atividades que demandem esforço de alta intensidade ${ }^{41}$. 


\section{Exercício físico durante a gestação: alterações no crescimento feto-placentário}

O termo exercício físico se refere a uma atividade física realizada sistematicamente. As adaptações fisiológicas associadas ao exercício físico dependem da intensidade, da duração e da freqüência do esforço ${ }^{47}$. O exercício físico pode ser classificado de acordo com a intensidade do esforço como: leve, moderado e intenso. Essa classificação toma como base a realização de alguns testes de esforço máximo para avaliar a concentração de lactato no sangue, o consumo máximo de oxigênio $\left(\mathrm{VO}_{2 \max }\right)$, e/ou a freqüência cardíaca máxima $\left(\mathrm{FC}_{\max }\right)$. Em exercícios de intensidade leve e moderada, a concentração de lactato no sangue permanece estável (variando entre $2 \mathrm{e}$ $4 \mathrm{mmol} / \mathrm{L})$. O VO ${ }_{2 \max }$ e a $\mathrm{FC}_{\text {max }}$ são os parâmetros fisiológicos mais comumente utilizados em estudos para referenciar a intensidade do esforço. Assim, um exercício leve geralmente se refere de 20 a $50 \%$ do $\mathrm{VO}_{2 \max }$ e da $\mathrm{FC}_{\text {max' }}$ um exercício moderado de $50-70 \%$ do $\mathrm{VO}_{2 \max }$ e da $\mathrm{FC}_{\text {max }}$ e o exercício intenso acima de $80 \%$ do $\mathrm{VO}_{2 \max }$ e da $\mathrm{FC}_{\max }$. Se o exercício físico é realizado regularmente é denominado de treinamento físico. Assim como o exercício físico, o treinamento físico pode ser classificado como leve, moderado e intenso ${ }^{47}$.

Durante um exercício físico, a taxa de fluxo sangüíneo visceral diminui enquanto o fluxo sangüíneo aumenta para os músculos e a pele. Há uma diminuição de $50 \%$ do fluxo sangüíneo para a placenta em resposta a exercícios moderados e intensos. Os níveis voltam ao normal logo após o término do exercício ${ }^{41}$.

O efeito do exercício sobre parâmetros fisiológicos da mãe (fluxo de sangue placentário e conteúdo de oxigênio e nutrientes na artéria) varia com o tipo, a freqüência, a duração e a intensidade do esforço, bem como o nível de aptidão física da mãe e o período da gestação no qual o programa de exercício físico teve início ${ }^{46}$. Estudos com humanos demonstram que, em gestantes não-exercitadas, o volume placentário na $20^{\circ}$ semana de gestação é cerca de $180 \mathrm{~mL}$, passando para $424 \mathrm{~mL}$ na $40^{\circ}$ semana $^{48}$. Em gestantes exercitadas $\left(60 \%\right.$ do $\mathrm{VO}_{2 \text { max }}$ ), o volume placentário na $20^{\circ}$ semana de gestação é de cerca $255 \mathrm{~mL}$ e na $40^{\circ}$ semana aumenta para $522 \mathrm{~mL}^{48}$. Uma carga de exercício físico moderado na primeira metade da gestação (60min, 5 dias por semana, $65 \%$ do $\mathrm{VO}_{2 \max }$ ) estimula o crescimento placentário. Ao contrário, passar de um exercício físico de baixa intensidade $\left(40 \%\right.$ do $\left.\mathrm{VO}_{2 \max }\right)$ na metade do período da gravidez, para um exercício físico intenso ( $>75 \%$ do $\mathrm{VO}_{2 \max }$ ) no final da gestação induz a diminuição do peso corporal para a idade gestacional em cerca de $370 \mathrm{~g}$ e o percentual de gordura de 12 para $8 \%{ }^{40}$.

Exercícios de intensidade mais leve apresentaram um menor aumento no volume placentário ${ }^{40}$. Contudo, a esta intensidade de esforço, foi observada uma diminuição na concentração de glicose sangüínea e de insulina durante e após a sessão de exercício ${ }^{46}$. Estes resultados fortalecem o papel benéfico do exercício físico na diminuição do risco de diabetes mellitus gestacional. Aliás, um estudo demonstrou que mulheres com diabetes gestacional e submetidas a uma dieta controlada e a exercício físico leve (20min, 3 vezes por semana, a $30 \%$ do $\mathrm{VO}_{2 \max }$ ) apresentaram menor concentração de glicose sangüínea e hemoglobina glicosilada, quando comparadas a mulheres submetidas unicamente a dieta controlada ${ }^{46}$.

$O$ treinamento físico leve durante a gestação aumenta o volume plasmático materno de repouso, o volume de sangue no espaço interviloso, o débito cardíaco, a função placentária e a taxa de crescimento fetal ${ }^{40}$. Há um aumento na disponibilidade de glicose no espaço placentário em resposta ao treinamento físico e isso vai repercutir no crescimento fetal ${ }^{41}$. O mecanismo de atuação inclui a regulação da síntese e liberação de peptídeos estimuladores do crescimento, como o fator de crescimento similar à insulina (IGF) dentro do compartimento fetal ${ }^{41}$. Quando a intensidade do esforço é aumentada, há uma redistri- 
buição do fluxo sangüíneo na mãe para os músculos em movimento. Isso causa uma diminuição temporária da quantidade de substrato e oxigênio disponível para a placenta. Dessa forma, em resposta ao exercício físico intenso, vários tecidos fetais liberam peptídeos que tornam o crescimento fetal mais lento, a exemplo, as proteínas ligantes do fator de crescimento similar à insulina (IGF-BP) ${ }^{48}$. Este efeito parece ser um mecanismo de proteção do feto que, se persistir, irá definir o tempo e o tipo de restrição do crescimento.

\section{Pode o exercício físico durante a gestação induzir a programação fetal?}

Os estudos sobre os efeitos a longo prazo do exercício físico durante o período de vida fetal ainda são escassos. Não há dados publicados com humanos e os modelos com animais avaliaram filhotes de ratos provindos de mães exercitadas até o período de desmame. Parnpiansil et al. ${ }^{49}$ verificaram que os filhotes de ratas exercitadas durante a gestação apresentaram um aumento, após o nascimento, na expressão do RNAm (ácido ribonucléico mensageiro) de fatores neurotróficos. Os autores correlacionaram este resultado ao aumento na habilidade de aprendizagem espacial (avaliado pelo teste de labirinto em " $\mathrm{T}$ "), quando comparados aos seus pares provindos de ratas não exercitadas.

Os estudos citados neste trabalho indicam que a atividade física materna e o aporte energético induzem adaptações fisiológicas na gestação e atuam como reguladores crônicos e agudos da disponibilidade de oxigênio e de substrato para o binômio mãe-filho. Parece que o principal fator que inicia a seqüência reguladora do crescimento é a disponibilidade de substrato e oxigênio provindos da mãe. O mecanismo subjacente inclui a liberação de mediadores como o fator de necrose tumoral alfa (TNF- $\alpha$ ) e o hormônio lactogênio placentário humano pela placenta, que regula suas concentrações de acordo com a disponibilidade de glicose e/ou outros fatores de crescimento feto-placentário ${ }^{41}$. O trofoblasto percebe a disponibilidade de nutrientes e oxigênio, isso pode alterar a expressão de genes e a subseqüente produção de múltiplos fatores supressivos ou estimuladores do crescimento.

Peptídeos reguladores adicionais incluem o sistema de fatores induzidos pela hipóxia (HIF), fatores de crescimento endotelial vascular (VEGF). Esses peptídeos são liberados em resposta às alterações locais na tensão de oxigênio, que influencia a angiogênese e a taxa de crescimento vascular e as alterações adaptativas na rede de capilares placentários ${ }^{40}$. Esse sistema funciona a partir de um feedback negativo no qual a tensão de oxigênio atua inversamente sobre o crescimento capilar $^{41}$.

O balanço energético durante a gestação é um fator importante que afeta a relação entre nutrição materna e o peso ao nascer. Mulheres sub-nutridas de comunidades rurais dos países em desenvolvimento, como a Índia e o Brasil, têm cargas altas de atividade física (trabalho agrícola e atividades domésticas) e seus filhos apresentam baixo peso ao nascer ${ }^{42,50}$. Extrema carga de trabalho também tem sido associada ao aumento da taxa de aborto e de nascimento de bebês prematuros ${ }^{42}$. Por outro lado, atividade física de baixa intensidade, e realizada sistematicamente, está associada ao aumento do peso ao nascer, mesmo em mulheres que passaram por privação dietética ${ }^{46}$.

Assim, estudos que avaliem os efeitos a longo prazo da atividade física, associada ou não à nutrição durante a gestação, devem ser priorizados. Este grupo de pesquisadores tem utilizado o rato como modelo experimental, e os dados preliminares apontam para o efeito benéfico do treinamento físico moderado durante a gestação na taxa de crescimento (até os 90 dias de vida) e na aquisição do padrão de atividade locomotora dos filhotes. Nos filhotes de mães treinadas e desnutridas, os danos causados pela desnutrição foram atenuados (dados não publicados). 


\section{CONCLUSÃO}

O ambiente influencia o crescimento e o desenvolvimento do filho. Vários estudos têm demonstrado o efeito do aporte inadequado de nutrientes durante a gestação e a ocorrência de doenças na vida adulta. O estilo de vida materno, representado pelo nível de atividade física, induz alterações no aporte de substratos e oxigênio no ambiente feto-placentário que repercutem no crescimento fetal e no peso ao nascer. Nesse sentido, é provável que a atividade física durante a gestação possa estar relacionada a alterações metabólicas na vida adulta. Da mesma forma, a atividade física também pode modular os efeitos da programação fetal induzida pela nutrição.

\section{COLABORADORES}

C.G. LEANDRO participou da elaboração do texto, da pesquisa em bases de dados e da redação final. M.F. AMORIM participou da revisão do texto e da pesquisa em bases de dados. S.M. HIRABARA, R. CURI e R.M. CASTRO participaram da revisão final do artigo.

\section{REFERÊ N CIAS}

1. Barker, DJ. The origins of the developmental origins theory. J Intern Med. 2007; 261(5):412-7.

2. Lucas A. Programming by early nutrition in man. Ciba Found Symp. 1991; 156:38-50. Discussion 50-5.

3. Burdge GC, Hanson MA, Slater-Jefferies JL, Lillycrop KA. Epigenetic regulation of transcription: a mechanism for inducing variations in phenotype (fetal programming) by differences in nutrition during early life? Br J Nutr. 2007; 97(6):1036-46.

4. Angelbeck JH, DuBrul EF. The effect of neonatal testosterone on specific male and female patterns of phosphorylated cytosolic proteins in the rat preoptic-hypothalamus, cortex and amygdala. Brain Res. 1983; 264(2):277-83.

5. Ponnappa BC, Rubin E. Modeling alcohol's effects on organs in animal models. Alcohol Res Health. 2000; 24(2):93-104.

6. Manhaes de Castro R, Barreto Medeiros JM, Mendes da Silva C, Ferreira LM, Guedes RC, Cabral
Filho JE, et al. Reduction of intraspecific aggression in adult rats by neonatal treatment with a selective serotonin reuptake inhibitor. Braz J Med Biol Res. 2001; 34(1):121-4

7. Mendes-da-Silva C, Souza SL, Barreto-Medeiros JM, Freitas-Silva SR, Antunes DE, Cunha AD, et al. Neonatal treatment with fluoxetine reduces depressive behavior induced by forced swim in adult rats. Arq Neuropsiquiatr. 2002; 60(4):928-31.

8. Silva Jr. VA, Vieira AC, Pinto CF, Paula TA, Palma $M B$, Lins Amorim MJ, et al. Neonatal treatment with naloxone increases the population of Sertoli cells and sperm production in adult rats. Reprod Nutr Dev. 2006; 46(2):157-66.

9. Barker DJ, Osmond C, Golding J, Kuh D, Wadsworth ME. Growth in utero, blood pressure in childhood and adult life, and mortality from cardiovascular disease. BMJ. 1989; 298(6673):564-7.

10. Ravelli GP, Stein ZA, Susser MW. Obesity in young men after famine exposure in utero and early infancy. N Engl J Med. 1976; 295(7):349-53.

11. Barker DJ, Osmond C. Diet and coronary heart disease in England and Wales during and after the Second World War. J Epidemiol Comm Health. 1986; 40(1):37-44.

12. Hales CN, Barker DJ, Clark PM, Cox LJ, Fall C, Osmond C, et al. Fetal and infant growth and impaired glucose tolerance at age 64. BMJ. 1991; 303(6809):1019-22.

13. Filho $M B$, Rissin $A$. A transição nutricional no Brasil: tendências regionais e temporais. Cad Saúde Pública. 2003; 19:S181-S91.

14. McCance RA. Food, growth, and time. Lancet. 1962; 2(7257):671-6.

15. Dobbing J. The influence of early nutrition on the development and myelination of the brain. Proc $R$ Soc Lond B Biol Sci. 1965; 159:503-9.

16. Costa-Cruz RR, Amancio-dos-Santos A, Guedes RC. Characterization of cortical spreading depression in adult well-nourished and malnourished rats submitted to the association of pilocarpine-induced epilepsy plus streptozotocin-induced hyperglycemia. Neurosci Letter 2006; 401(3):271-5.

17. Do Monte-Silva KK, Assis FL, Leal GM, Guedes RC. Nutrition-dependent influence of peripheral electrical stimulation during brain development on cortical spreading depression in weaned rats. Nutr Neurosci. 2007; 10(3-4):187-94.

18. Barreto-Medeiros J, Queiros-Santos A, Cabral-Filho JE, Ferreira ESWT, Leandro CG, Deiro TC, et al. Stress/aggressiveness-induced immune changes are altered in adult rats submitted to neonatal 
malnutrition. Neuroimmunomodulation. 2007; 14(5):229-334.

19. Barros KM, Manhaes-De-Castro R, Lopes-De-Souza S, Matos RJ, Deiro TC, Cabral-Filho JE, et al. A regional model (Northeastern Brazil) of induced mal-nutrition delays ontogeny of reflexes and locomotor activity in rats. Nutr Neurosci. 2006; 9(1-2):99-104.

20. Lopes de Souza S, Orozco-Solis R, Grit I, Manhaes de Castro R, Bolanos-Jimenez F. Perinatal protein restriction reduces the inhibitory action of serotonin on food intake. Eur J Neurosci. 2008; 27(6):1400-8.

21. Toscano AE, Amorim MA, Carvalho Filho EV, Aragao RS, Cabral-Filho JE, Moraes SR, et al. Do malnutrition and fluoxetine neonatal treatment program alterations in heart morphology? Life Sci. 2008; 82(21-22):1131-6.

22. Toscano AE, Manhaes-de-Castro R, Canon F. Effect of a low-protein diet during pregnancy on skeletal muscle mechanical properties of offspring rats. Nutrition. 2008; 24(3):270-8.

23. Berney DM, Desai M, Palmer DJ, Greenwald S, Brown A, Hales CN, et al. The effects of maternal protein deprivation on the fetal rat pancreas: major structural changes and their recuperation. J Pathol. 1997; 183(1):109-15.

24. Lesage J, Hahn D, Leonhardt M, Blondeau B, Breant $B$, Dupouy JP. Maternal undernutrition during late gestation-induced intrauterine growth restriction in the rat is associated with impaired placental GLUT3 expression, but does not correlate with endogenous corticosterone levels. J Endocrinol. 2002; 174(1):37-43.

25. Ozanne SE, Olsen GS, Hansen LL, Tingey KJ, Nave $\mathrm{BT}$, Wang $\mathrm{CL}$, et al. Early growth restriction leads to down regulation of protein kinase $C$ zeta and insulin resistance in skeletal muscle. J Endocrinol. 2003; 177(2):235-41.

26. Cottrell EC, Ozanne SE. Early life programming of obesity and metabolic disease. Physiol Behav. 2008; 94(1):17-28.

27. Cripps RL, Archer ZA, Mercer JG, Ozanne SE. Early life programming of energy balance. Biochem Soc Trans. 2007; 35(Pt 5):1203-4.

28. Martin-Gronert MS, Tarry-Adkins JL, Cripps RL, Chen JH, Ozanne SE. Maternal protein restriction leads to early life alterations in the expression of key molecules involved in the aging process in rat offspring. Am J Physiol Regul Integr Comp Physiol. 2008; 294(2):R494-500.

29. Petrik J, Reusens B, Arany E, Remacle C, Coelho C, Hoet JJ, et al. A low protein diet alters the balance of islet cell replication and apoptosis in the fetal and neonatal rat and is associated with a reduced pancreatic expression of insulin-like growth factorII. Endocrinology. 1999; 140(10):4861-73.

30. Zambrano E, Rodriguez-Gonzalez GL, Guzman C, Garcia-Becerra R, Boeck L, Diaz L, et al. A maternal low protein diet during pregnancy and lactation in the rat impairs male reproductive development. J Physiol. 2005; 563(Pt 1):275-84.

31. Hoppe CC, Evans RG, Moritz KM, Cullen-McEwen LA, Fitzgerald SM, Dowling J, et al. Combined prenatal and postnatal protein restriction influences adult kidney structure, function, and arterial pressure. Am J Physiol Regul Integr Comp Physiol. 2007; 292(1):R462-9.

32. Woodall, SM, Johnston BM, Breier BH, Gluckman PD. Chronic maternal undernutrition in the rat leads to delayed postnatal growth and elevated blood pressure of offspring. Pediatr Res. 1996; 40(3):438-43.

33. Bayol S, Jones D, Goldspink G, Stickland NC. The influence of undernutrition during gestation on skeletal muscle cellularity and on the expression of genes that control muscle growth. Br J Nutr. 2004; 91(3):331-9.

34. Sawaya AL, Martins PA, Grillo LP, Florencio TT. Long-term effects of early malnutrition on body weight regulation. Nutr Rev. 2004; 62 (7 Pt 2): S127-33.

35. Sawaya AL, Dallal G, Solymos G, Sousa MH, Ventura $\mathrm{ML}$, Roberts $\mathrm{SB}$, et al. Obesity and malnutrition in a Shantytown population in the city of Sao Paulo, Brazil. Obes Res. 1993; 3(Suppl 2):107s-15s.

36. Sichieri R, Moura AS, Godoy JL, Niero N, Matsumoto FN. Nutritional status of children and occupational categories of the family in a rural community of Parana, Brazil]. Cad Saúde Pública. 1993; 9(Suppl 1):28-35.

37. Florencio TT, Ferreira HS, Cavalcante JC, Luciano SM, Sawaya AL. Food consumed does not account for the higher prevalence of obesity among stunted adults in a very-low-income population in the Northeast of Brazil (Maceio, Alagoas). Eur J Clin Nutr. 2003; 57(11):1437-46.

38. Sinclair SK, Lea RG, Rees WD, Young LE. The developmental origins of health and disease: current theories and epigenetic mechanisms. Soc Reprod Fertil Suppl. 2007; 64:425-43.

39. Smith FM, Garfield AS, Ward A. Regulation of growth and metabolism by imprinted genes. Cytogenet Genome Res. 2006; 113(1-4):279-91.

40. Clapp JF, Kim H, Burciu B, Schmidt S, Petry K, Lopez B. Continuing regular exercise during pregnancy: 
effect of exercise volume on fetoplacental growth. Am J Obstet Gynecol. 2002; 186(1):142-7.

41. Clapp JF. Influence of endurance exercise and diet on human placental development and fetal growth. Placenta. 2006; 27(6-7):527-34.

42. Rao S, Kanade A, Margetts BM, Yajnik CS, Lubree $\mathrm{H}$, Rege $\mathrm{S}$, et al. Maternal activity in relation to birth size in rural India. The Pune Maternal Nutrition Study. Eur J Clin Nutr. 2003; 57(4):531-42.

43. ACOG Committee Opinion. Number 267, January 2002: exercise during pregnancy and the postpartum period. Obstet Gynecol. 2002; 99(1):171-3.

44. Perkins CC, Pivarnik JM, Paneth N, Stein AD. Physical activity and fetal growth during pregnancy. Obstet Gynecol. 2007; 109(1):81-7.

45. Hatch MC, Shu XO, McLean DE, Levin B, Begg M, Reuss $L$, et al. Maternal exercise during pregnancy, physical fitness, and fetal growth. Am J Epidemiol. 1993; 137(10):1105-14.

46. Clapp JF. Effects of Diet and Exercise on Insulin Resistance during Pregnancy. Metab Syndr Relat Disord. 2006; 4(2):84-90.
47. Leandro CG, Manhaes de Castro R, Nascimento E, Pithon-Curi TC, Curi R. Mecanismos adaptativos do sistema imunológico em resposta ao treinamento físico. Rev Bras Med Esporte. 2007; 13(5): 343-8.

48. Thomas DM, Clapp JF, Shernce S. A foetal energy balance equation based on maternal exercise and diet. J R Soc Interface. 2008; 5(21):449-55.

49. Parnpiansil P, Jutapakdeegul N, Chentanez T, Kotchabhakdi N. Exercise during pregnancy increases hippocampal brain-derived neurotrophic factor mRNA expression and spatial learning in neonatal rat pup. Neurosci Lett. 2003; 352(1): 45-8.

50. Lima M, Ismail S, Ashworth A, Mies SS. Influence of heavy agricultural work during pregnancy on birth weight in North-East Brazil. Int J Epidemiol. 1999; 28(3):469-74.

Recebido em: 10/8/2007

Versão final reapresentada em: 8/8/2008

Aprovado em: 18/11/2008 